\title{
User fee exemptions are not enough: out-of-pocket payments for 'free' delivery services in rural Tanzania
}

\author{
Margaret E. Kruk', Godfrey Mbaruku², Peter C. Rockers ${ }^{3}$ and Sandro Galea ${ }^{3}$ \\ 1 Department of Health Management and Policy, University of Michigan School of Public Health, Ann Arbor, MI, USA; Averting \\ Maternal Death and Disability Program, Mailman School of Public Health, Columbia University, NY, USA \\ 2 Ifakara Health Research and Development Centre, Dar-es-salaam, Tanzania \\ 3 Department of Epidemiology, University of Michigan School of Public Health, Ann Arbor, MI, USA
}

Summary oвjective To identify the main drivers of costs of facility delivery and the financial consequences for households among rural women in Tanzania, a country with a policy of delivery fee exemptions. METHODS We selected a representative sample of households in a rural district in western Tanzania. Women who given birth within 5 years were asked about payments for doctor's/nurse's fees, drugs, non-medical supplies, medical tests, maternity waiting home, transport and other expenses. Wealth was assessed using a household asset index. We estimated the proportion of women who cut down on spending or borrowed money/sold household items to pay for delivery in each wealth group. RESULTS In all, $73.3 \%$ of women with facility delivery reported having made out-of-pocket payments for delivery-related costs. The average cost was 6272 Tanzanian shillings (TZS), [95\% Confidence Interval (CI): 4916, 7628] or 5.0 United States dollars. Transport costs $(53.6 \%)$ and provider fees $(26.6 \%)$ were the largest cost components in government facilities. Deliveries in mission facilities were twice as expensive as those in government facilities. Nearly half $(48.3 \%)$ of women reported cutting down on spending or borrowing money/selling household assets to pay for delivery, with the poor reporting this most frequently.

CONCLUSION Out-of-pocket payments for facility delivery were substantial and were driven by high transport costs, unofficial provider payments, and preference for mission facilities, which levy user charges. Novel approaches to financing maternal health services, such as subsidies for transport and care from private providers, are required to reduce the cost barriers to attended delivery.

keywords maternal health services, health financing, out-of-pocket payments, delivery costs

\section{Introduction}

There were an estimated 536000 maternal deaths worldwide in 2005, nearly all in developing countries. These deaths persist despite longstanding knowledge of interventions that, if implemented universally, could reduce that number dramatically (Campbell \& Graham 2006b; WHO, UNICEF, UNFPA 2007). These interventions include care by skilled birth attendants and emergency obstetric care for women with complications (Campbell \& Graham 2006a). However, deliveries by a skilled attendant and facility delivery rates are still very low in many developing countries. Sub-Saharan Africa, which has the highest maternal mortality ratios globally, has average facility delivery rates of only $47 \%$, according to recent surveys (MEASURE DHS 2008).
Health care financing is a central determinant of access to skilled delivery care. At the national level, general tax financing together with policies of universal coverage have been linked to high service coverage and low maternal mortality in Sri Lanka, Malaysia, and Kerala, India (Borghi et al. 2006b). In a cross-national study of developing countries, a higher proportion of government financing of health was found to be associated with greater utilization of skilled birth attendants, controlling for confounders (Kruk et al. 2007). In contrast, out-of-pocket payments for delivery are a barrier to use of health facilities (Ensor \& Ronoh 2005; Borghi et al. 2006a; Parkhurst et al. 2006). Much of the research focus has been on user fees, which have been shown to reduce use of health services by the poor in particular (Nanda 2002; Pokhrel et al. 2005). The disincentive impact of user fees is worst in rural, agricultural areas 
where families' access to cash is seasonal (Soucat et al. 1997).

In addition to user fees, several studies have found that women in many parts of the world face substantial out-ofpocket costs for drugs, supplies (gloves, syringes, plastic sheets), informal payments (e.g. tips), and transport of the mother and any birth companions (Nahar \& Costello 1998; Khan 2005). For example, travel costs were over half of all delivery costs of normal deliveries in Nepal (Borghi et al. 2006a). Out-of-pocket financing of the costs of facility delivery has been shown to have substantial financial repercussions on households. These include having to borrow money or sell valuable household items, which makes families more vulnerable to impoverishment (Russell 1996; McIntyre et al. 2006).

Tanzania is a low income country with a maternal mortality ratio of 950 per 100000 live births; over 100 times higher than industrialized countries.(WHO, UNICEF, UNFPA 2007) Tanzania's total health spending in 2004 was 12 United States dollars (USD) per capita; of this 5.2 USD was government spending. Private spending on health comprised primarily out-of-pocket spending by households: of the 6.8 USD in private spending 5.6 USD was out-of-pocket spending, while 0.3 USD came from private insurance spending, and approximately 0.8 USD from other private spending (e.g. employers, non-governmental organizations) (WHO 2007). The government is the major provider of health services with private (mainly faith-based) organizations providing one-third of all health services (National Bureau of Statistics of Tanzania 2007). In an effort to reduce maternal mortality, like several other governments in developing countries, Tanzania's government has declared maternal and child health services, including facility delivery, to be exempt from user fees in government facilities (Wilkinson et al. 2001; United Republic of Tanzania Ministry of Health 2003; Witter et al. 2007). Furthermore, the government and the churches have created an extensive network of primary health facilities, including nearly 5000 dispensaries, which are in principle equipped to care for women with uncomplicated deliveries (National Bureau of Statistics of Tanzania 2007). However, in 2004 , only $33.6 \%$ of women living in rural areas reported delivering their last child in a health facility (National Bureau of Statistics of Tanzania \& ORC Macro 2004).

The aim of this study was to identify the main drivers of cost for facility delivery and the financial consequences on households in a population-based sample of women in rural Tanzania. Based on this evidence we suggest several policy recommendations for financing reforms to increase skilled delivery rates.

\section{Methods}

\section{Study area and sampling}

The study was conducted in Tanzania's Kasulu District, an isolated primarily rural area located in Kigoma Region, near the country's western border with the Democratic Republic of Congo. The district has a total population of 630000 and includes one main town, Kasulu (population 33 000). Most people in the district are subsistence farmers. The vast majority of the population belongs to the Muha tribe and speaks both Kiha, the local language, and Swahili, the national language.

The district has 55 functioning government facilities (48 dispensaries, six health centres and one district hospital) and 13 mission facilities (nine dispensaries, two health centres, and two hospitals) along with two refugee camp health centres that also cater to the adjacent district population (for the purposes of this analysis, the refugee health centres were included as 'mission' facilities). The district policy is that normal deliveries be conducted at dispensaries or health centres, with complicated cases referred to the hospital. There is also a private maternity waiting home in Kasulu town that is used by some women from distant villages, particularly those with complicated pregnancies.

This study employed a three-stage representative cluster sample of rural households from Kasulu District, omitting Kasulu town. Power calculations indicated a target sample of 1000 women was required to differentiate the likelihood of key outcomes of interest in the study. Of 89 villages in Kasulu District, 50 were chosen in the first stage, with probability proportional to size, based on the 2002 Tanzania census. The sampled villages had anywhere from 2-5 subvillages (approximately 100 households) one of which was randomly selected from each village. The leader of that subvillage provided a list of households within the subvillage from which 35 households were selected through random systematic sampling. Inclusion criteria limited participants to women over the age of 18 with a delivery within the 5 years prior to recruitment. The National Institute for Medical Research in Tanzania as well as the Institutional Review Board at the University of Michigan provided ethics clearance for the study. Written consent was obtained from all respondents.

\section{Instrument and survey fielding}

Questionnaires and consent documents were developed in English then translated into Swahili and back translated. Questionnaires included information related to household composition, characteristics and assets (indicators of socioeconomic status/wealth), childbirth history, 
knowledge and perception of the local health care system, and barriers to health care utilization.

The questionnaire was administered between June and mid-July, 2007. Interviews were done by two teams of trained interviewers fluent in Kiswahili and English. Each team also had at least one interviewer fluent in Kiha. Each interview was carried out face-to-face and lasted approximately $30 \mathrm{~min}$. Quality was monitored by a supervisor who observed two or more interviews per day.

\section{Measures and data analysis}

In addition to demographic and facility use questions, each woman with a facility delivery was asked what she paid for various components of her delivery including doctor's/nurse's fees, drugs, non-medical supplies, medical tests, transport, maternity waiting home and other expenses. Maternity waiting homes in Tanzania are private, but are available to women delivering in public and private facilities, thus their costs were included in the cost of delivery for both private and public patients. A sensitivity analysis using only women that gave birth in the previous 6 months was done to assess the level of recall bias for cost data. Women were also asked for the total cost of delivery, whether they had to cut down on household spending or borrow money/sell household items to afford the delivery costs, and their perceptions of the quality of care at different types of facilities. All costs were inflation adjusted to their 2007 value, using Tanzanian gross domestic product (GDP) deflator values published by the (International Monetary Fund (2007)). A principal components analysis based on an index of 10 household assets (radio, bicycle, number of bed-nets, etc.) was conducted to determine a continuous indicator of wealth. Based on this households were allocated into wealth quintiles (quintile one was poorest, quintile five richest) (Filmer \& Pritchett 2001; Schellenberg et al. 2003; Vyas \& Kumaranayake 2006). All statistical analysis was done using SAS-Callable SUDAAN adjusting for the cluster design of the survey (Research Triangle Institute 2005).

\section{Results}

Of the 1322 eligible respondents recruited for the study, 1205 (91.1\%) women completed questionnaires (112 were not at home on repeated visits and five refused participation). One woman failed to report the location of her most recent birth and was excluded from this analysis. Table 1 provides summary statistics for the 1204 women included in this analysis: $23.9 \%$ were under the age of 25 , and $27.5 \%$ had never attended school at the time of survey administration. The sample of women surveyed were
Table I Sociodemographic and health care utilization characteristics of a population-based sample of rural women from Kasulu District, Western Tanzania, 2007 (N = 1204*)

\begin{tabular}{lrr}
\hline Characteristics & $n$ & $(\%)$ \\
\hline Demographics & & \\
$\quad$ Age & & \\
$\quad<25$ & 588 & $(23.9)$ \\
$\quad 25-34$ & 343 & $(47.1)$ \\
$\quad \geq 35$ & 331 & $(27.5)$ \\
$\quad$ No schooling & 1186 & $(98.5)$ \\
Occupation farmer or fisher & 1153 & $(95.8)$ \\
Currently married & 1184 & $(98.3)$ \\
Ethnicity muha & & \\
Religion & 1097 & $(91.1)$ \\
$\quad$ Christian & 89 & $(7.4)$ \\
$\quad$ Muslim & & \\
$\quad$ Number of living children & 155 & $(12.9)$ \\
$\quad 0-1$ & 539 & $(44.8)$ \\
$\quad 2-4$ & 501 & $(41.6)$ \\
$\quad 5$ or more & & \\
Household assets & 7 & $(0.6)$ \\
Electricity & 134 & $(11.1)$ \\
More than two meals a day & 824 & $(68.4)$ \\
At least one mosquito net & & \\
Location of delivery & 731 & $(60.7)$ \\
Home $\dagger$ \\
Health facility $\ddagger$ \\
On the way to a health facility & 32 & $(2.7)$ \\
& & \\
\hline
\end{tabular}

*Totals may not add up to 1204 due to missing value.

†Of the 731 women, 717 gave birth in their own home, 11 in another's home, and three in a field.

tOf the 441 women, 100 gave birth in a government dispensary, 61 gave birth in a government health centre, 72 gave birth in a government hospital, 86 gave birth in a mission dispensary, 71 in a mission health centre, 48 in a mission hospital, three in unknown facilities.

nearly all of Muha ethnicity (98.3\%), Christian religion $(91.1 \%)$, and worked as either farmers or fishers $(98.5 \%)$. Three in ten $(31.6 \%)$ women lived in households without a mosquito net, and only seven women $(0.6 \%)$ lived in a household with electricity. Only $11.1 \%$ of women's families ate more than two meals a day. Among the 1204 women included in the analysis, $441(36.6 \%)$ delivered their most recent child in a health facility. From this group, for the cost analysis, one woman was removed due to item non-response and three women with payments over 70000 Tanzanian shillings (TZS) (56.22 USD) and without medical complications were also removed as outliers. In addition, two women were removed from the analysis due to missing year of delivery, which did not permit proper adjustment of their costs. The resulting sample included 435 women. 
M. E. Kruk et al. User fee exemptions are not enough

Figure I Distribution of total costs of facility delivery, for a population-based sample of rural women from Kasulu District, Western Tanzania, 2007 $(n=435)$. Total cost includes cost of provider, drugs, diagnostic tests, transportation, maternity waiting home, supplies, and unknown. For all facility deliveries with reported costs: $n=435$, mean $=6272$ Tanzanian shillings (TZS) [5.04 United States dollars (USD)], median $=3193$ TZS (2.56 USD); for facility deliveries with payment: $n=319$, mean $=8553$ TZS $(6.87$ USD), median $=4790$ TZS (3.85 USD).

${ }^{\mathrm{a}} 1245$ TZS $=1$ USD. ${ }^{\mathrm{b}}$ Maximum payment $=70000$ TZS (56.2 USD).

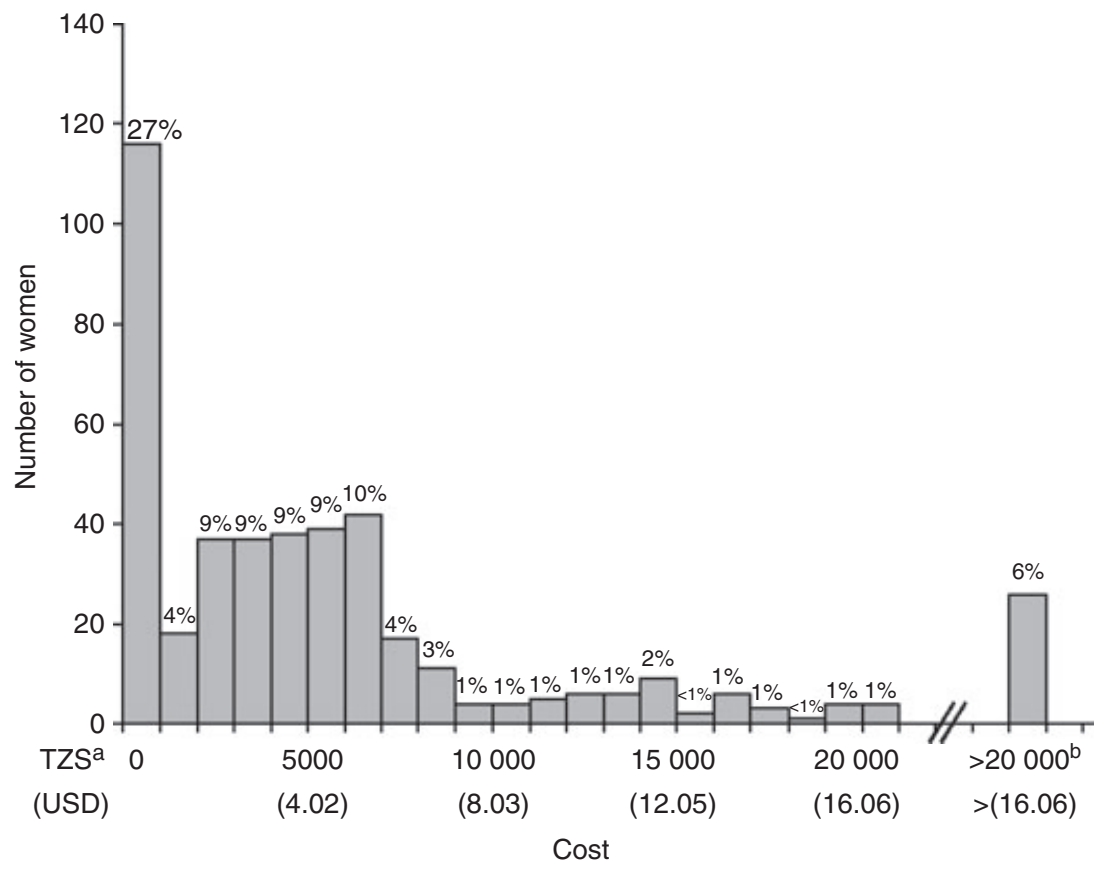

Figure 3 shows a comparison of the components of delivery costs between government and mission facilities for the 262 respondents who provided component information. For deliveries at government facilities for which women reported cost components, the average cost of delivery was 6268 TZS (95\% CI: 4459-8077). On average, these women paid 3362 TZS (53.6\%) (95\% CI: 1780 4944) for transportation to and from the delivery facility, 1668 TZS (26.6\%) (95\% CI: 931-2405) for provider fees, 569 TZS (9.1\%) (95\% CI: 70-1069) for drugs and diagnostic services, 532 TZS (8.5\%) (95\% CI: -38-1102) for staying in a maternity waiting home, and 137 TZS (2.2\%) (95\% CI: 64-209) for supplies used during delivery. For deliveries at mission facilities, the average cost of delivery was 10642 TZS (95\% CI: 7380-13 904). On average, these women paid 1638 TZS (15.4\%) (95\% CI: 280-2995) for transportation to and from the delivery facility, 6077 TZS (57.1\%) (95\% CI: 4710-7444) for provider fees, 2320 TZS (21.8\%) (95\% CI: 676-3965) for drugs and diagnostic services, 605 TZS (5.7\%) (95\% CI: 133-1077) for staying in a maternity waiting home, and two TZS $(<0.1 \%)(95 \% \mathrm{CI}:-2-5)$ for supplies used during delivery. More detailed component cost information is available in Appendix 2. Of special note is the fact that $84.6 \%$ of women that delivered in a government dispensary reported paying provider costs (compared to $35.7 \%$ at government health centres and $30.0 \%$ at government hospitals). The results of a sensitivity analysis showed no meaningful recall bias for component costs. 
M. E. Kruk et al. User fee exemptions are not enough

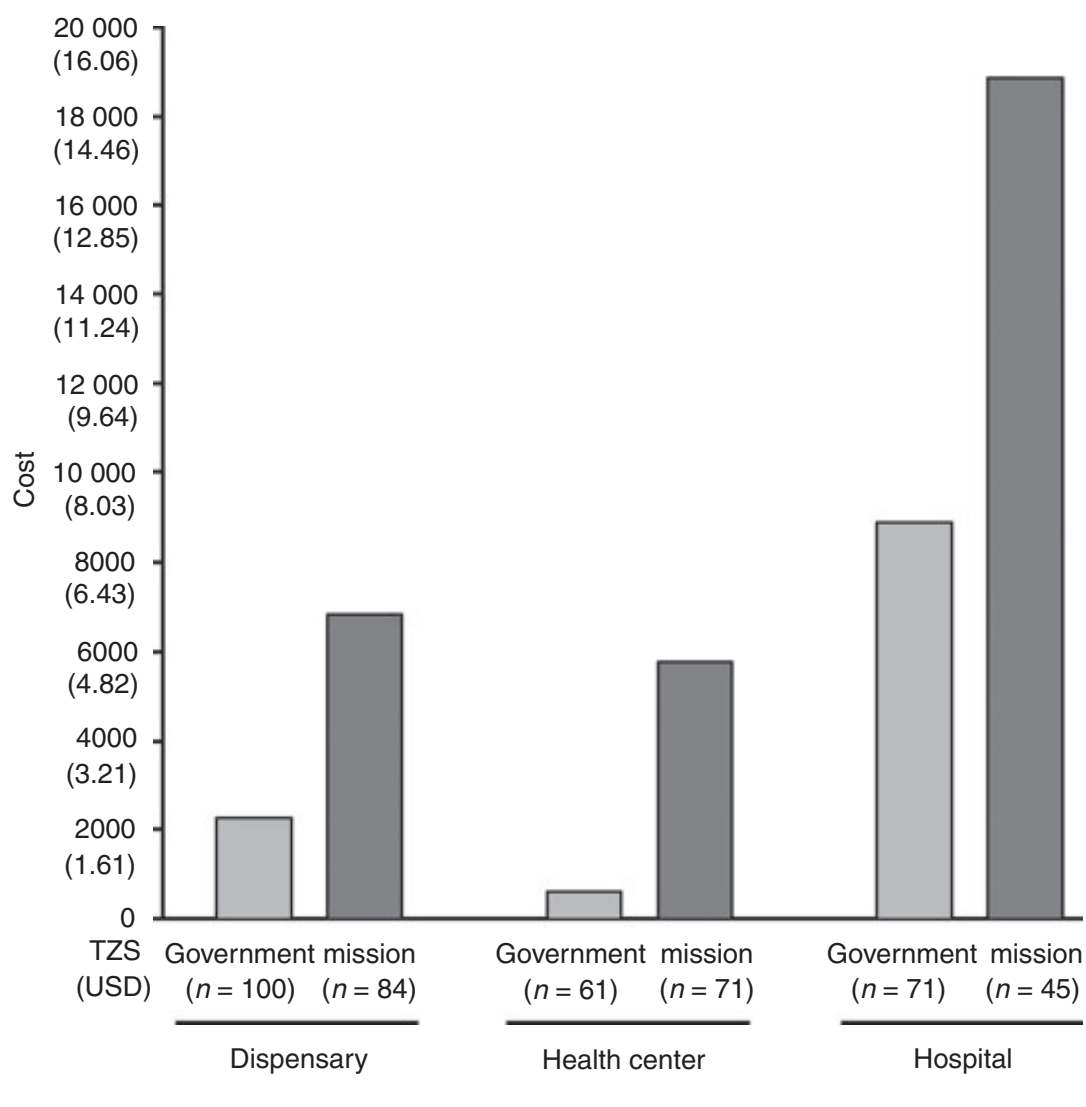

Delivery facility ownership and level
Figure 2 Average total cost for facility delivery by facility ownership and level, for a population-based sample of rural women from Kasulu District, Western Tanzania, $2007(n=432)$. The frequencies of reporting any costs by facility type were: $73.0 \%$ at government dispensaries, $26.2 \%$ at government health centres, $78.9 \%$ at government hospitals, $95.2 \%$ at mission dispensaries, $67.6 \%$ at mission health centres and $100.0 \%$ at mission hospitals: $67.3 \%$ of all costs were incurred at mission facilities.
Figure 4 shows how the surveyed households coped financially to afford the costs of delivery across wealth groups. The percentage of women who cut down on spending to cope with the financial burden of paying for delivery, starting with the most poor and moving towards to least poor, was $50.0 \%, 44.7 \%, 39.2 \%, 36.7 \%$, and $32.1 \%$, respectively. On average, $40.6 \%$ of women cut down on spending. The percentage of women who either borrowed money or sold personal belongings to cope with the financial burden of paying for delivery, starting with the most poor and moving towards to least poor, was $42.7 \%, 40.4 \%, 44.3 \%, 34.4 \%$, and $22.6 \%$. On average, $36.8 \%$ of women either borrowed money or sold personal belongings. These data are descriptive; no statistical analysis was attempted as each quintile had a relatively small number of women. Overall, $48.3 \%$ resorted to either borrowing/selling or cutting down on spending. The women perceived dispensaries to provide relatively poor quality of care compared with health centres and hospitals: $44.8 \%$ reported less than very good care quality at their nearest dispensary compared with $28.3 \%$ at the health centre and $21.6 \%$ at the hospital (see Appendix 3).

\section{Discussion}

Despite the Tanzanian government's commitment to universal provision of free maternal health services, we found that nearly three-quarters of women who delivered in a facility in a rural district of Tanzania reported paying for delivery. The average cost of facility delivery was 6272 TZS or 5.0 USD, even when taking into account women who reported paying nothing. The proportion of mothers in our survey reporting any payment was much higher than was found in the nationally-representative 1993 Living Standards Measurement Survey, in which only $40.3 \%$ of women surveyed reported paying anything for delivery (Prata et al. 2004). However, the amount paid was roughly consistent with a smaller non-representative sample in another district of Tanzania that found expenditures of 5.9 USD at health centres (Kowalewski et al. 2002). The delivery costs reported here are equivalent to $1.7 \%$ of Tanzania's per capita GDP and $41.7 \%$ of the country's per capita total health expenditure (WHO 2007). This amount may be prohibitive in a rural population that relies on subsistence farming for its livelihood: almost half of the 


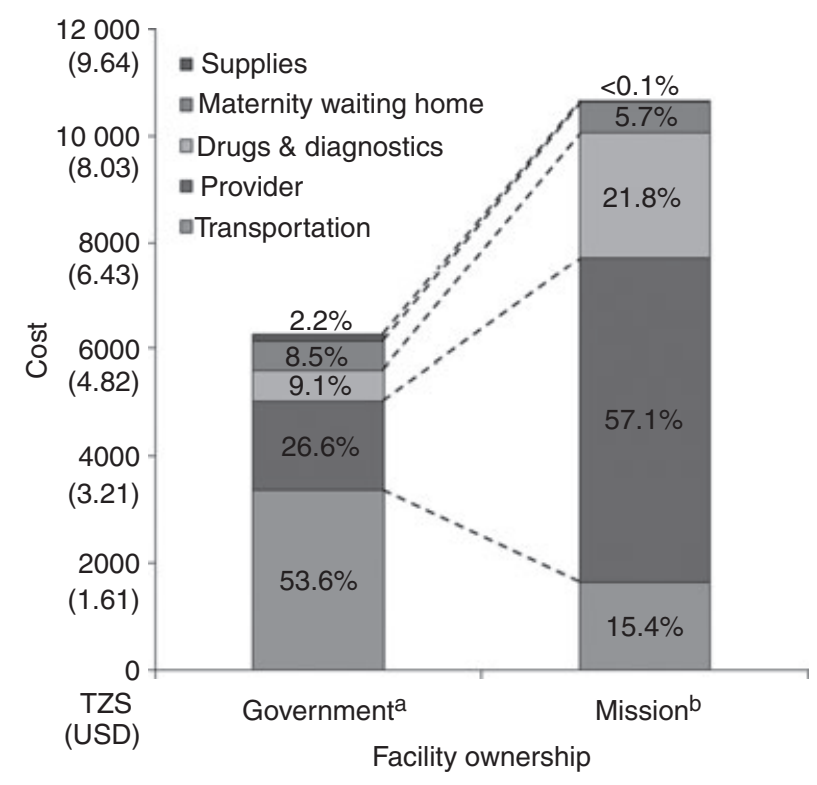

Figure 3 Components of total delivery cost, for a populationbased sample of rural women from Kasulu District, Western Tanzania, 2007 ( $n=262)$. Components include: Provider (doctor's/nurse's fees, both official and unofficial); Drugs and Diagnostics (medicines and any medical tests, including radiologic procedures such as X-rays); Maternity Waiting Home (private facility where some women stay in the last phases of pregnancy); Supplies (e.g., gauze, plastic sheeting, IV tubing, blankets),

Transport (e.g., fare, fuel costs). ${ }^{a} n=129$; mean $=6,268$ TZS (5.03 USD). ${ }^{\mathrm{b}} n=133$; mean $=10642 \mathrm{TZS}(8.55 \mathrm{USD})$.

women reported that their households had to cut down on other spending, borrow money, or sell household assets to afford delivery costs. The cost of delivery in government facilities was driven by two factors: transport costs and unofficial fees charged by health providers. Moreover, we found that frequent use of mission facilities raised the average cost of delivery in the district.

Just over half the costs of delivery in a government facility was for transport to the facility; by comparison $37.9 \%$ of the costs were for direct medical costs (provider, drugs, diagnostics and supplies). Over $30 \%$ of women who delivered in a government facility travelled to the district hospital in Kasulu, the only government facility to offer comprehensive emergency obstetric care. For this subset of women transportation was $71.0 \%$ of the total costs. As noted earlier, high transport costs for maternal and child health services have been found in other studies of rural populations in the developing world (Afsana 2004; Borghi et al. 2006a). Here, the preference for hospital delivery in a district with an extensive network of government primary care facilities may indicate a lack of confidence in the ability of the lower level dispensaries and health centres to attend to labour complications due to a lack of medicines and equipment or poor provider practice - indeed in our sample, women indicated that hospitals provided better quality of care than dispensaries. Others have documented deficiences in the quality of care at dispensaries in Tanzania (Leonard \& Masatu 2007).

The second major contributor to delivery costs in government facilities was provider payments. In the context of the national policy of user fee exemption for maternal care, these payments represent unofficial or under-the-table payments to providers. It is particularly concerning that $85 \%$ of women delivering at the lowest government primary care level - the dispensary - reported paying the provider as the dispensary is meant to expand access to maternity care, particularly to rural populations and services are meant to be free. Thus some if not all of these payments represent informal or under-the-table payments. Informal charges at the dispensary may also be contributing to the low observed facility delivery rates in
Figure 4 Financing coping mechanisms to afford facility delivery, by wealth, for a population-based sample of rural women from Kasulu District, Western Tanzania, $2007(n=429)$.
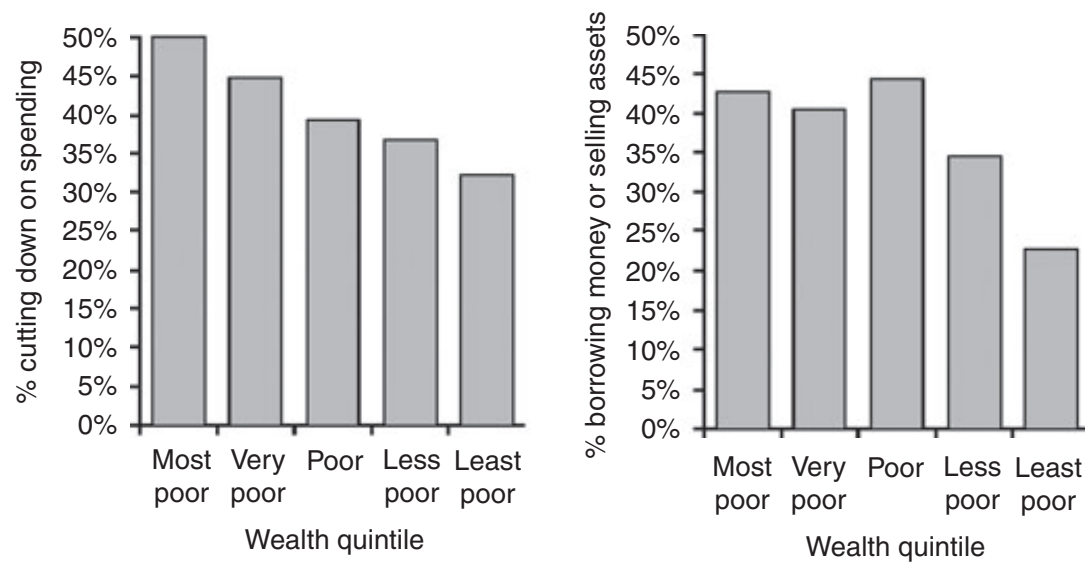
this population, with fewer than $40 \%$ of women delivering in a facility. This may also have equity implications as women who deliver at their local dispensary may be poorer and less able to choose other facilities for delivery. Facility fees, including informal fees, reduce the number of deliveries in medical facilities in several developing countries, particularly among the poor (Stekelenburg et al. 2004; Hotchkiss et al. 2005; Witter et al. 2007). Interestingly, provider payments were reported much less frequently at the government hospital perhaps due to greater financial transparency, better supervision, greater provider professionalism, and higher salaries at that level compared to the dispensary (Lewis 2007).

Lastly, and perhaps somewhat unexpectedly in this rural district with a pre-dominantly poor, farming population and wide availability of cheaper (if not free) government facilities, frequent use of mission facilities was a major contributor to average delivery cost in the district. Nearly half of the women with facility deliveries chose to deliver in mission facilities and compared with their peers using government facilities those women reported a higher frequency of out-of-pocket payments $(86.5 \%$ vs. $62.5 \%)$ and much higher average costs: 9148 TZS (7.3 USD) $v s$. 3840 TZS (3.1 USD). Approximately $80 \%$ of the costs in mission facilities were for direct medical costs: provider fees, drugs, diagnostic tests and supplies. Women who delivered in a mission facility paid nearly four times more on these direct medical costs than women who delivered in a government facility. The high use of mission facilities contradicts earlier qualitative research suggesting that the poor prefer government facilities (Mamdani \& Bangser 2004). Similar to women's preference for the government hospital, the use of mission facilities is likely driven by quality considerations: mission facilities in Tanzania have a reputation for better service and have been shown to be better equipped and to provide more competent care than government facilities (Mamdani \& Bangser 2004; Leonard \& Masatu 2007; National Bureau of Statistics of Tanzania 2007). The fact that at least some women in this population were willing to pay more than twice as much to deliver in mission facilities rather than government facilities underlines the importance of quality of care to women in rural areas. There is a growing body of work that supports the importance of quality in selecting health services in poor populations (Gilson et al. 1994; Audo et al. 2005; Levesque et al. 2006).

We found that the payments for delivery were frequently a source of financial hardship in this population. Approximately $41 \%$ of women who delivered in a facility reported having to cut down on other spending to pay for delivery costs and $37 \%$ of women reported having to borrow money or sell household assets.
Cutting down on spending and borrowing or selling were much more common among the poorest quintile of women than among the least poor quintile: $50 \%$ in the poorest group reported cutting down on spending and $43 \%$ having to borrow or sell assets vs. $32 \%$ and $22 \%$, respectively, for the least poor. This pattern of inequity in household financing is broadly consistent with findings from a 1993 national survey in which $28 \%$ of women reported selling assets to pay for delivery care - with rates of $50 \%$ among the poor and $18 \%$ among the least poor (Prata et al. 2004). Borrowing or selling are not only immediate stressors for families coping with an impending or recent birth but these modes of financing also expose families to the risk of asset depletion and impoverishment (Kawabata et al. 2002; Liu et al. 2003; Bogale et al. 2005). As a result, health economists have noted that the willingness to pay (i.e., having made a payment) is not equivalent to the ability to pay (Russell et al. 1995; McIntyre et al. 2006).

Our findings have to be interpreted in the context of several limitations. First, the recall of women for costs may recede with time, particularly for deliveries several years previously. Although women with deliveries in the past 5 years were eligible to participate, $84 \%$ of the women in this analysis delivered their last child within the previous 2 years, thus reducing recall error. In addition, a sensitivity analysis using costs from deliveries within 6 months of the survey showed that recall bias was minimal. The number of women with data on components of facility costs was relatively small, leading to large confidence intervals around the estimates. Lastly, the survey results cannot be extrapolated to other, particularly, urban populations in Tanzania or elsewhere.

Long-term health system reforms and substantially higher health spending are both likely required to address under-the-table payments and quality issues in government dispensaries that are motivating women to select more distant government hospitals and mission facilities (McPake et al. 2000; Lerberghe et al. 2002). However, several innovative financing approaches to reduce the costs of transport and delivery in private facilities are being tried right now in other countries to reduce those cost barriers to attended delivery. For example, as part of its Reproductive and Child Health Program, the government of India has introduced vouchers that women can use to pay for any mode of transport (e.g., private cares, tractors) from the village to health facilities for delivery. The owners of the transport can then exchange the vouchers for cash (Bhatia et al. 2006). Reducing the costs and availability of emergency transport may also persuade more women to deliver in facilities: a key feature of the successful Sri Lankan effort 
to increase facility deliveries and reduce maternal mortality was the free provision of ambulance services that link primary care facilities and hospitals with advanced obstetric care (Koblinsky et al. 1999).

Contracting with private providers to provide agreed-on services has improved coverage and equity in several developing and post-conflict countries (Loevinsohn \& Harding 2005). In one financing experiment, the state government of Gujarat in India has introduced a scheme, Chiranjeevi Yojana ('eternal life scheme'), to pay private obstetricians a capitated fee for assisting in the deliveries of women living below the poverty line. Women can then select any private provider enroled in the scheme without having to make any payment at the point of care. This was meant both to increase facility delivery and to reduce the financing burden of delivery costs for poor households. While it is too early to assess the effects of the scheme on the these output indicators, $61 \%$ of the private obstetricians in the district have thus far enroled (Loevinsohn \& Harding 2005). In addition, the provision of subsidies to private facilities may enable them to reduce charges, thus increasing access to the poorest segments of the population (Ngalande Banda \& Simukonda 1994).

Lastly, the charging of informal fees at dispensaries needs to be addressed by policymakers. While a full discussion of all the factors leading to the charging of informal fees is outside the scope of this discussion, measures that have shown success in reducing such charges include improved supervision and community level accountability (publicizing the fee exemption policy on clinic walls, on radio and in newspapers, exit interviews with women, etc.). In the longer term, improvement in salaries and work conditions may reduce incentives for informal fee charging (Lewis 2007) Some of these factors appear to be at work in the government hospital in the study district where fewer patients reported provider fees.

Our findings suggest that in addition to user fee exemptions, developing countries need to consider a range of other health care financing strategies to achieve universal coverage of attended delivery and to reduce the financing burden on families already using the health system. Given the disproportionate financial impact of delivery costs on the poor, the suggested policy changes will likely be pro-poor and thus help to close the welldocumented gap between rich and poor in rates of attended delivery in developing countries (Houweling et al. 2007).

\section{Acknowledgements}

This work was funded by the William Davidson Institute at the Ross School of Business of the University of Michigan and the Averting Maternal Death and Disability Program at the Mailman School of Public Health at Columbia University. The funders did not have any involvement in conducting the study or in deciding to submit the manuscript for publication.

\section{References}

Afsana K (2004) The tremendous cost of seeking hospital obstetric care in Bangladesh. Reproductive Health Matters 12, 171180.

Audo MO, Ferguson A \& Njoroge PK (2005) Quality of health care and its effects in the utilisation of maternal and child health services in Kenya. East African Medical Journal 82, 547-553.

Bhatia M, Yesudian C, Gorter A et al. (2006) Demand side financing for reproductive and child health services in India. Economic and Political Weekly, January 21, 279-284.

Bogale T, Mariam DH \& Ali A (2005) Costs of illness and coping strategies in a coffee-growing rural district of Ethiopia. Journal of Health Population and Nutrition 23, 192-199.

Borghi J, Ensor T, Neupane BD et al. (2006a) Financial implications of skilled attendance at delivery in Nepal. Tropical Medicine and International Health 11, 228-237.

Borghi J, Ensor T, Somanathan A et al. (2006b) Mobilising financial resources for maternal health. Lancet 368, 1457-1465.

Campbell OM \& Graham WJ (2006a) Strategies for reducing maternal mortality: getting on with what works. Lancet 368 , 1284-1299.

Ensor T \& Ronoh J (2005) Effective financing of maternal health services: a review of the literature. Health Policy 75, 49-58.

Filmer D \& Pritchett LH (2001) Estimating wealth effects without expenditure data - or tears: an application to educational enrollments in states of India. Demography 38, 115-132.

Gilson L, Alilio M \& Heggenhougen K (1994) Community satisfaction with primary health care services: an evaluation undertaken in the Morogoro region of Tanzania. Social Science and Medicine 39, 767-780.

Hotchkiss DR, Krasovec K, El-Idrissi MD et al. (2005) The role of user charges and structural attributes of quality on the use of maternal health services in Morocco. The International Journal of Health Planning and Management 20, 113-135.

Houweling TA, Ronsmans C, Campbell OM et al. (2007) Huge poor-rich inequalities in maternity care: an international comparative study of maternity and child care in developing countries. Bulletin of the World Health Organization 85, $745-754$.

International Monetary Fund (2007) World Economic Outlook, International Monetary Fund, Washington, DC. Database.

Kawabata K, Xu K \& Carrin G (2002) Preventing impoverishment through protection against catastrophic health expenditure. Bulletin of the World Health Organization 80, 612.

Khan S (2005) Free does not mean affordable: maternity patient expenditures in a public hospital in Bangladesh. Cost Effectiveness and Resource Allocation 3, 1.

Koblinsky M, Campbell OM \& Heichelheim J (1999) Organizing delivery care: what works for safe motherhood? Bulletin of the World Health Organization 77, 399-406. 
M. E. Kruk et al. User fee exemptions are not enough

Kowalewski M, Mujinja P \& Jahn A (2002) Can mothers afford maternal health care costs? User costs of maternity services in rural Tanzania African Journal of Reproductive Health 6, 65-73.

Kruk ME, Galea S, Prescott M et al. (2007) Health care financing and utilization of maternal health services in developing countries. Health Policy Plan 22, 303-310.

Leonard KL \& Masatu MC (2007) Variations in the quality of care accessible to rural communities in Tanzania. Health Affairs 26, w380-w392.

Lerberghe WV, Conceicao C, Damme WV et al. (2002) When staff is underpaid: dealing with the individual coping strategies of health personnel. Bulletin of the World Health Organization 80, 581-584.

Levesque JF, Haddad S, Narayana D et al. (2006) Outpatient care utilization in urban Kerala, India. Health Policy Plan 21, 289-301.

Lewis M (2007) Informal payments and the financing of health care in developing and transition countries. Health Affairs (Millwood) 26, 984-997.

Liu Y, Rao K \& Hsiao WC (2003) Medical expenditure and rural impoverishment in China. Journal of Health Population and Nutrition 21, 216-222.

Loevinsohn B \& Harding A (2005) Buying results? Contracting for health service delivery in developing countries. Lancet 366, 676-681.

Mamdani M \& Bangser M (2004) Poor people's experiences of health services in Tanzania: a literature review. Reproductive Health Matters 12, 138-153.

McIntyre D, Thiede M, Dahlgren G et al. (2006) What are the economic consequences for households of illness and of paying for health care in low- and middle-income country contexts? Social Science and Medicine 62, 858-865.

McPake B, Asiimwe D, Mwesigye F et al. (2000) Coping strategies of health workers in Uganda. Studies in Health Services Organisation and Policy 16, 157-162.

MEASURE DHS (2008) Measure DHS Statcompiler, ORC Macro, Calverton, MD.

Nahar S \& Costello A (1998) The hidden cost of 'free' maternity care in Dhaka, Bangladesh. Health Policy Plan 13, 417-422.

Nanda P (2002) Gender dimensions of user fees: implications for women's utilization of health care. Reproductive Health Matters 10, 127-134.

National Bureau of Statistics of Tanzania (2007) Tanzania Service Provision Assessment Survey 2006. National Bureau of Statistics of Tanzania, Dar es Salaam.

National Bureau of Statistics of Tanzania \& ORC Macro (2004) Tanzania DHS 2004, ORC Macro, Calverton, MD.

Ngalande Banda EE \& Simukonda HP (1994) The public/private mix in the health care system in Malawi. Health Policy Plan 9, 63-71.
Parkhurst JO, Rahman SA \& Ssengooba F (2006) Overcoming access barriers for facility-based delivery in low-income settings: insights from Bangladesh and Uganda. Journal of Health Population and Nutrition 24, 438-445.

Pokhrel S, Hidayat B, Flessa S et al. (2005) Modelling the effectiveness of financing policies to address underutilization of children's health services in Nepal. Bulletin of the World Health Organization 83, 338-344.

Prata N, Creig F, Walsh J et al. (2004) Ability to pay for maternal health services: what will it take to meet WHO standards? Health Policy 70, 163-174.

Research Triangle Institute (2005) SUDAAN Software, Research Triangle Park, NC.

Russell S (1996) Ability to pay for health care: concepts and evidence. Health Policy \& Planning 11, 219-237.

Russell S, Fox-Rushby J \& Arhin D (1995) Willingness and ability to pay for health care: a selection of methods and issues. Health Policy \& Planning 10, 94-101.

Schellenberg JA, Victora CG, Mushi A et al. (2003) Inequities among the very poor: health care for children in rural southern Tanzania. Lancet 361, 561-566.

Soucat A, Levy-Bruhl D, De Bethune X et al. (1997) Affordability, cost-effectiveness and efficiency of primary health care: the Bamako Initiative experience in Benin and Guinea. International Journal of Health Planning and Management 12 (Suppl. 1), S81-S108.

Stekelenburg J, Kyanamina S, Mukelabai M et al. (2004) Waiting too long: low use of maternal health services in Kalabo, Zambia. Tropical Medicine and International Health 9, 390-398.

United Republic of Tanzania Ministry of Health (2003) Tanzania National Health Policy. Ministry of Health (Tanzania), Dar es Salaam, Tanzania.

Vyas S \& Kumaranayake L (2006) Constructing socio-economic status indices: how to use principal components analysis. Health Policy Plan 21, 459-468.

WHO (2007) World Health Organization Statistical Information System: Core Health Indicators. WHO, Geneva.

WHO, UNICEF, UNFPA et al. (2007) Maternal Mortality in 2005: Estimates Developed by WHO, UNICEF, UNFPA and The World Bank. World Health Organization, Geneva.

Wilkinson D, Gouws E, Sach M et al. (2001) Effect of removing user fees on attendance for curative and preventive primary health care services in rural South Africa. Bulletin of the World Health Organization 79, 665-671.

Witter S, Arhinful DK, Kusi A et al. (2007) The experience of Ghana in implementing a user fee exemption policy to provide free delivery care. Reproductive Health Matters 15, 61-71.

Corresponding Author Margaret E. Kruk, Department of Health Management and Policy, University of Michigan School of Public Health, 109 Observatory Road, SPH II M3166, Ann Arbor, MI 48109, USA. Tel.: 1734615 3633; Fax: 1734764 4338; E-mail: mkruk@umich.edu 


\section{E. Kruk et al. User fee exemptions are not enough}

Appendix 1. Average total cost for facility delivery by facility ownership and level, for a population-based sample of rural women from Kasulu District, Western Tanzania, $2007(n=432)$

\begin{tabular}{|c|c|c|c|c|}
\hline Delivery facility ownership level & $n$ & Mean (TZS) & $95 \% \mathrm{CI}(\mathrm{TZS})$ & \\
\hline \multicolumn{5}{|l|}{ Dispensary } \\
\hline Government & 100 & 2258 & 1065 & 3450 \\
\hline Mission & 84 & 6816 & 5669 & 7962 \\
\hline \multicolumn{5}{|l|}{ Health Centre } \\
\hline Government & 61 & 604 & -84 & 1293 \\
\hline Mission & 71 & 5751 & 2842 & 8661 \\
\hline \multicolumn{5}{|l|}{ Hospital } \\
\hline Government & 71 & 8849 & 5190 & 12507 \\
\hline Mission & 45 & 18859 & 11742 & 25977 \\
\hline
\end{tabular}

Appendix 2. Component costs for delivery services by delivery facility for a population-based sample of rural women from Kasulu District, Western Tanzania, $2007(n=262)$

\begin{tabular}{|c|c|c|c|c|c|c|}
\hline & \multicolumn{3}{|l|}{ Government } & \multicolumn{3}{|l|}{ Mission } \\
\hline & Dispensary & Health centre & Hospital & Dispensary & Health centre & Hospital \\
\hline$n$ & 65 & 14 & 50 & 63 & 37 & 33 \\
\hline \multicolumn{7}{|l|}{ Component cost* } \\
\hline Provider & $2606 \dagger$ & $304 t$ & $830 \mathbb{S}$ & 5376 & 3944 & 9808 \\
\hline Drugs \& diagnostics & 184 & 190 & 1200 & 1219 & 601 & 6387 \\
\hline Transportation & 0 & 1597 & 8227 & 88 & 4297 & 1615 \\
\hline Maternity waiting home & 93 & 190 & 1198 & 425 & 391 & 1191 \\
\hline Supplies & 104 & 278 & 139 & 0 & 0 & 7 \\
\hline
\end{tabular}

*In TZS $(1,245$ TZS = 1 USD).

$\dagger 55(84.6 \%)$ women reported making a provider payment for delivery at government dispensaries.

$\$ 5(35.7 \%)$ women reported making a provider payment for delivery at government health centres.

$\$ 15(30.0 \%)$ women reported making a provider payment for delivery at the government hospital.

Appendix 3. Perceived quality of care at nearest health facilities for a population-based sample of rural women from Kasulu District, Western Tanzania, $2007(n=435)$

\begin{tabular}{lrr}
\hline & $n$ & $\%$ \\
\hline Less than very good quality of care & 195 & 44.8 \\
Nearest dispensary & 123 & 28.3 \\
Nearest health centre & 94 & 21.6 \\
Nearest hospital & 188 & 43.2 \\
Nearest hospital or health centre better quality than nearest dispensary & 19 \\
Nearest dispensary better quality than nearest hospital and health centre & 4.4 \\
\hline
\end{tabular}

